various a class of invalids, may be said of other places named in this paper so far as they approach in locality, elevation and other prerequisites, so beautifully and aptly commingled by nature at this point. It is easy of access, being a railroad centre. Six roads entering from every point of the compass. The best educational advantage being the proud home of Colorado College, unsurpassed public schools, together with the religious denominations of every name well represented, and most of them possessing fine church edifices, and not a saloon in the city.

In conclusion, I am confident that when the advantage of these localities in high altitudes are thoroughly known and understood by the medical profession, thousands who must die by remaining in other localities, will be sent to these places and restored to health.

\section{CHOLESTEATOMA OF THE EAR.}

Read in the Section of Laryngology and Otology, at the Forth-first Annual Meeting of the American Medical Association, at Vash ville, Tenn., May, 1890 .

BY B. ALEX. RANDALL, A.M., M.D., PROFESSOR OF DISEASES OF THE EAR IN THE PHILADELPHIA PULYCliNic, ETC.

The subject of cholesteatoma has received a tir considerable amount of attention on both sides of the Atlantic, yet seems one to which further attention can be profitably devoted. Writers on pathological anatomy are apt to be silent on this point, as though true cholesteatoma were a very rare tumor, met almost solely on the brain membranes; or else they strongly combat the claim that the ear is a frequent seat of the growth. Aural surgeons, on the other hand, too often regard these cases as only desquamative inflammations, and draw no distinction between mere aggregations of exfoliated epidermis and the true pearly tumor. The reason is not far to seek. Desquamative conditions are frequently met, and are open to ready study; cholesteatomata are generally buried in the bony cavities, and are removable only piecemeal during life, and are then nothing more than epidermal shreds, almost indistinguishable from any other flaky masses.

Waiving in great part the question of how often the cholesteatomatous masses met in clinical work are to be viewed as tumors in the strictest sense, I would like to draw attention to their frequent occurrence and their serious importance. A recent statement of Virchow's fittingly opens the discussion: "Of the fatally-ending cases of middle-ear suppuration among us, nearly one-third are to be ascribed to this form of growth," 1 -a statement that for force and authority could hardly be surpassed, and needs no additional citation of authorities. Having had no personal ac-

Trans, Berlin Med. Soc., I 889 , p. $5^{8}$, Atch. f. Ohrenh., xxviii October I8, I 889 . quaintance with fatal cases of cholesteatoma, not having met them in the few fatal ear cases (generally with meningitis or brain abscess) which I have studied post-mortem, I will turn to the question of its clinical occurrence in the non-fatal cases, which make up in frequency for their presumably lesser gravity. Many varieties of the condition will be met, differing widely in their characteristics, and to this is due the varying names that have been applied, and the divergent views entertained as to their nature. For instance, a colored woman of 50 years, came a year since to the Polyclinic complaining of deafness, tinnitus and some vertigo, growing steadily worse for some months. Both auditory canals were blocked with yellowish, horny masses, which were with much difficulty removed entire. The record showed that similar collections had been removed four years previously, and the diagnosis then made of desquamative otitis externa, corresponds with cases published by Buck, Pomeroy and others. Both drum membranes had been previously destroyed by long-standing suppuration, probably with caries, and the exposed tympanic cavities were lined with cicatricial tissue of the same pearly lustre as the material removed from them. The meatus walls were not free from traces of exfoliating epidermis, but it was very evident that the plugs were derived from within the tympana, as the desquamation of the pearly lining. 'The connection of the inmost part of the mass to the tympanic wall was partly organic, and broken only by force; and no clear distinction could be made between the most recent portion of the removed mass and that which still covered the promontory, and bled when lightly scratched. The absence of suppuration made the study easy in this instance.

More often pus is present when the case comes for treatment, and the condition is thereby much obscured. Such was the case of an inmate of the Deaf and Dumb Institution, Lizzie W., æt. 9, seen May I 2, I 888 . Cleansing of the discharge from the right meatus showed a large destruction of the drum membrane, with apparent loss of all three ossicles, and stuffing of all the depressions with white, flaky epidermis. This was removed with great difficulty by syringe, probe and forceps in alternation, and it is very doubtful if the attic and antrum have ever been emptied. A dark point the size of a pin's head, halfway out the posterior wall of the canal, called for investigation, and proved the summit of a similar epithelial mass lodged in the neighborhood of the antrum. The small opening in the skin was stretched in dragging forth the material within, until it revealed an opening in the bony wall through which a large pea might pass; and the cavity within, when finally emptied, was found to measure nearly i 5 millimetres in each dimension. The laminated masses of epidermis removed from it would have filled a drachm vial. Only 
after numerous sittings was approximate completeness attained in the cleansing. Then suppuration promptly ceased-to recur once or twice in the past year, when the collection of epithelium had formed anew.

A still more notable case was that of a fellowpupil in the same institution, Susan C., æt. I4, who was brought with suppuration of both ears. The greatly altered tympanic cavities were so tightly packed with pearly epidermis, that only after six or eight sittings of half an hour's duration, when forceps, probe, curette and syringe were used to the exhaustion of both patient and surgeon, were the tympana emptied. Drum membranes and ossicles were gone on each side, and a glazed cicatricial tissue covered the visible surfaces. At the next visit the right ear was dry; but on the left some suppuration continued, a few epidermal flakes were visible, and the probe and curved forceps drew away a good deal more of the same material from the attic and the entrance to the antrum. Although now clean, as far as sight and touch could determine, continued syringing was ordered, unless the ear remained perfectly dry. This was carried out for three days, and when next seen, there was found a cholesteatomous mass filling the auditory canal, and measuring on removal $26 \times 8 \times 6 \mathrm{~mm}$. It was doubtless swollen by imbibition of fluid, but after drying was still nearly as large in each dimension; and one could but wonder where there had been room in the temporal bone for it to hide itself. Suppuration at once ceased, and has recurred only once or twice for short periods, and on this side alone.

So large a proportion of the deaf-mute patients whom I have treated presented this condition in greater or less degree, that I now expect it in the old suppurative cases, and distrust any negative findings until after repeated examination; and I always order the cases showing it to return within a couple of months, even if the ear remains apparently free from any suggestion of trouble. Some of them do so, and renewed collections are generally found; others suffer a renewal of the otorrhoea before the time set for their return, and the removal of the fresh collection is followed by prompt cessation of the discharge.

The first notable case of this kind which I met was Margaret M., æt. about 35, who came in January, I883, to the Episcopal Hospital. She was very deaf, and spoke a scarcely intelligible German dialect, so that little was learned of the history or subjective symptoms, except that she suffered much with dizziness. Examination showed the left canal clear, and the drum membrane largely destroyed and altered almost past recognition by thickening and adhesions, evidently the results of old, long-standing suppurative disease. On the right the canal was blocked with a mass, apparently cerumen, and its removal showed a condition of the deeper structures closely similar to that on the left. The endeavor to inflate the tympanic cavities probably failed, but some relief seemed to have been obtained. At her second visit, a scale of dark material was still present on the posterior wall of the right meatus, and it was removed as a matter of principle, since several cases of sinus in such a situation had recently been seen. A large sintus was revealed, from which an astonishing mass of material was removed, most of which resembled moist buckskin, but the central portions of which were dry, opalescent, and closely laminated. The walls of the cavity were moist with a pus of strong odor, having a pungency rather characteristic of cholesteatomatous masses. Further relief followed this clearing. At a subsequent visit, the walls of the cavity were found dry, smooth and firm except in the innermost part. The portions visible through the opening in the meatus wall were pale, cicatricial and glazed. The opening into the wall of the canal was found to measure $12 \mathrm{~mm}$. in each dimension; and the cavity in the mastoid extended from the level of the meatus floor to i $2 \mathrm{~mm}$. above its roof, and a curved probe could be passed I $_{5}$ mm. directly backward, and its tip could be brought so far outward as to show that little bone was left between it and the skin. We had therefore a cavity some $20 \mathrm{~mm}$. in height, I $5 \mathrm{~mm}$. antero-posteriorly, and extending from near the surface of the mastoid at least $30 \mathrm{~mm}$. inward. Two points were found up and in where the probe met no bony resistance, and pressure caused vertigo and faintness, probably from pressure on the meninges. There was some further improvement in hearing, and less dizziness; but advance soon ceased, and as she was near confinement, she dropped out of sight. The wonder was in this case, that there was room in the mastoid for such a cavity; and there was probably here a beginning of that encroachment of the mass upon the cranial cavity, which has been so marked in some of the fatal cases described.

In a closely similar case more recently seen, the woman was seriously ill, with high fever, severe pain, and much mastoid tenderness on the right; but the acute symptoms were in large part due to a developing quinsy. Polypoid masses filled the meatus, and by their recurrence after removal, obscured the condition; but enough epithelial flakes were removed at the first sitting to indicate the probable nature of the trouble. Cleansing with syringe, probe and forceps, was pushed as far each time as the patient's condition permitted, and when last seen, two months later, the large cavity above and behind was clear and dry, except for the trace of discharge which came from some granulations on the inner lip of the sinus, where the polypus had formerly grown around a small carious point. Instillation of warm water showed that the capacity of the cav- 
ity and canal was at least double that of the normal canal upon the other side. A fraction of the hearing had been gained, and the patient considered herself well.

In each of the cases cited, the formation was quite surely secondary to destructive suppurative inflammation; and the cases are extremely few where this can be excluded, and the growth regarded as primary. Yet such cases have been reported by Lucae, Kuhn, and others, as occurring in the mastoid without perforation or other evidence of previous inflammatory trouble; and similar growths have occurred independently upon or in the drum membrane. Politzer has found small pearly bodies in the mucous membrane of the promontory, clearly comparable to those usually met in epithelioma, and probably ready to develop, under favoring conditions, into the conspicuous masses under discussion. Primary cholesteatoma of the ear must, therefore, be accepted as a reality, and as probably less rare here than in other situations. Secondary cholesteatoma, varying from pearly tumors, distinguishable only by their nuclear mass of caseous matter, if at all, from the primary, to mere desquamative masses of indeterminate form and structure, are of quite frequent occurrence. Toynbee noted ten such tumors, aside from epidermal collections in the external meatus, among $\mathrm{I}, \mathrm{Or} 3$ diseased temporal bones, and all observers of wide experience confirm such findings. Their importance lies largely in their tendency to form insidiously in cavities, where they are out of sight and reach, and to maintain and aggravate the inflammatory processes of which they are usually the results. Continued growth leads to absorption by pressure of the surrounding walls, widening the cavities and laying open the important adjacent fossæ. Huge tumors of this sort have been found invading the cranial cavity, and leading to fatal brain disease. The lateral sinus has been laid open by them, and thrombosis or hæmorrhage has ensued, with fatal outcome; or septic osteitis has been set up, with resulting pyæmia. These are their more direct results : they constantly interfere mechanically with the drainage in suppurating cases, increasing the danger, extending the destruction, and forming most serious obstacles to successful treatment. Their removal is often very difficult, and their recurrence probable and dangerous; so the claim with which this paper opened, that they are worthy of most careful study, seems fairly sustained. Awkward as is the name cholesteatoma, its employment in this connection has no small value; for it better suggests the importance and tendency of the pathological condition than does the misleading, if correct, term, desquamative inflammation. Many of the text-books regard these conditions as ustually belonging merely to the external auditory canal; and I believe that many students have, like my- self, winnowed the instructive from the misleading in these descriptions only after some trying personal experiences have furnished a much needed key. That there may be others to whom the subject is almost unknown, is my reason for placing upon record these incomplete notes.

DIAGNOSIS AND OPERATIVE TREATMENT OF GUNSHOT WOUNDS OF THE STOMACH AND INTESTINES.

Read by Invitation in the Surgical Section of the Tenth Internationat Medical Congress, August 8, 1890.

BY N. SENN, M.D., PH.D., of MrLWAUKEE, WIS.

ATTENDING SURGEON MILWAUKEE HOSPITAL; PROFESSOR PRINCIPLES OF SURGERY AND SURGICAL PATHOLOGY IN RUSH MEDICAL COLLEGE, CHICAGO, ILL.

(Continued from $p$. 320.)

Hydrogen Gas Test as Applied in the Diagnosis of Perforating Gunshot Wounds of the Abdomen.

I have up to the present time applied this test in over one hundred cases of gunshot wounds of the abdomen intentionally produced in dogs, and in every instance where the stomach or intestine was wounded, the visceral complication was positively diagnosed before the abdomen was opened; hence I have no reason to make any retraction from the claim previously made, that the test is infallible in making a positive differential diagnosis before abdominal section is made, between a simple penetrating gunshot wound of the abdomen and a penetrating wound complicated by visceral wounds of the gastro-intestinal canal.

In all these experiments the animal was strapped on one of Pasteur's operating tables, the $a b-$ domen shaved, and after the animal was fully under the influence of an anæsthetic, the shooting was done with a 32 -calibre revolver. Rectal inflation of hydrogen gas was practiced immediately after the shot was fired, and after its diagnostic indications were carefully studied and noted, the abdomen was opened and its contents examined for visceral injuries. In all cases where the colon was perforated, inflation could be done under very slight pressure, as the gas readily escaped into the peritoneal cavity and from there through the wound of entrance, where it was ignited as it escaped. If the perforation of the intestine was located above the ileo-cæcal valve, more pressure was required, as the resistance offered by the ileo-cæcal valve had to be overcome before the small intestine could be inflated. I will cite only one of the many experiments.

"Experiment 65.-Dog, weight twenty-five pounds. Under full anæsthesia the animal was shot in the abdomen, the bullet passing nearly in a transverse direction through the abdominal cavity, an inch and a half below the umbilicus, 